\title{
GAMBARAN UMUM SECTIO CAESAREA BERDASARKAN UMUR DAN PEKERJAAN DI RUANG PERAWATAN KEBIDANAN RSUD LAKIPADADA KABUPATEN TANA TORAJA
}

\author{
Dynastin Since Pakita
}

\author{
Akademi Perawat Toraya Kabupaten Tana Toraja
}

Alamat Korespondensi : (pdynastin@gmail.com/085242268730)

\begin{abstract}
ABSTRAK
Sectio caesarea adalah suatu persalinan buatan ,dimana janin dilahirkan melalui suatu insisipada dinding perut dan dinding rahim dengan sayatan rahim dalam keadaan utuh serta berat janin di atas 500 gram (Sarwono ,2007).Penelitian ini bertujuan untuk mengetahui gambaran umum Post Sectio Caesarea Berdasarkan Umur dan Pekerjaan di RSUD Lakipadada Kabupaten Tana Toraja Tahun 2013.Variabel independent yaitu umur dan pekerjaan Variabel dependent yaitu Sectio Caesarea.Metode penelitian ini merupakan deskriptif. Populasi dalam penelitian ini adalah keseluruhan data tentang wanita yang mengalami seksio caesarea di ruang obgyn yang telah di register di RSUD Lakipadada tahun 2013 dengan jumlah 586 responden dengan jumlah sampel 457 responden, teknik pengambilan sampel adalah total sampling.Pengumpulan data yang digunakan adalah data sekunder yang diperoleh dari buku register persalinan RSUD Lakipadada Tahun 2013.Pengolahan dilakukan secara manual menggunakan kalkulator dan disajikan dalam tabel distribusi frekuensi dengan persentase dalam bentuk narasi/ penjelasan. Hasil yang didapat dari penelitan ini adalah terdapat $457(77,99 \%)$ kasus dengan sectio caesarea , sedangkan persalinan normal $129(22,01 \%)$, umur :<20 dan $>35$ sebanyak 141 oraang $(30,85 \%)$ sedangkan resiko rendah 316 responden ( $69,15 \%)$ dan pekerjaan :Ibu Rumah Tangga sebanyak 410 responden $(89,71 \%$ ) dan pegawai 47 responden ( $10,29 \%)$.
\end{abstract}

Kata Kunci : Pekerjaan, Umur, Sectio Caesarea

\section{PENDAHULUAN}

Menurut definisi WHO kematian maternal ialah kematian seresponden wanita hamil atau sesudah berakhirnya kehamilan oleh sebab apapun. jumlah yang diperoleh pada kematian ibu di tahun 2006 negara - negara maju yang umumnnya berkisar antara 1,5 dan 3,0 per 10.000 kelahiran hidup dan di tahun 2007 kematian ibu sebanyak 3,2 jiwa pertahun. WHO memperkirakan peningkatan jumlah kematian ibu pada tahun 2008 data statistik dari banyaknya jumlah penduduk pertahun. (Anggreni L, online diakses 16 Juli 2014).

Angka kejadian seksio sesarea di Indonesia menurut data survey nasional pada tahun 2007 adalah 921.000 dari 4.039 .000 persalinan atau sekitar $22.8 \%$ dari seluruh persalinan (Agreni L, diakses 15 juli 2014). Sedangkan angka kejadian seksio sesarea di Provinsi pada tahun 2008 berjumlah 3.401 operasi dari 170.000 persalinan atau sekitar $20 \%$ dari seluruh persalinan.

Data dines kesehatan tentang seksio caesarea yaitu dari 320 persalinan $(100 \%)$ terdapat 195 persalinan normal $(60,94 \%), 80$ persalinan patologis $(25 \%)$ dan 45 persalinan dengan seksio sesarea (14,06\%) dengan indikasi partus macet 17 responden $(37,78 \%)$,
Cepalo Pelvic Disease 6 responden $(13,33 \%)$, Placenta Previa 10 responden $(22,22 \%)$, Solutio Placenta 3 responden $(6,67 \%)$, Rupture Uteri 1 responden (2,22\%), Gemeli 2 responden $(4,44 \%)$, letak lintang 3 responden $(6,67 \%)$ dan Serotinus 3 responden $(6,67 \%)$. 45 ibu post seksio sesarea tersebut dengan anestesi spinal $100 \%$ baru melakukan mobilisasi dini (miring ke kanan dan ke kiri) setelah 24 jam pascabedah. Data yang didapatkan dari dinas kesehatan Provinsi Sulawesi Selatan tahun 2009 ditemukan 4,305 kasus seksio sesarea dan meningkat 530,44 \% pada tahun 2010 menjadi 8366 kasus (profil dinas kesehatan Sulawesi S elatan).Data yang diperoleh dari RSUD Lakipadada tahu 2012 di temukan kasus 339 section caesare (data RSUD Lakipadada,2012). Berdasarkan data yang di dapat dari register ruang obgyn RSUD Lakipadada ,jumlah kasus seksio caesarea pada tahun 2013 adalah 457 responden.

Berdasarkan data yang di dapat dari 2 tahun yang lalu jumlah kasus seksio caesarea menegalami peningkatan ,sehingga penulis tertarik untuk melakukan penelitian mengenai gambaran umum post seksio caesarea berdasarkan umur dan pekerjaan. 


\section{BAHAN DAN METODE}

Lokasi, Populasi, Sampel

Penelitian ini merupakan deskriptif dimana peneliti ingin melihat kejadian masa lampau dengan tujuan memperoleh Gambaran Umum Tentang Sectio Caesarea Berdasarkan Umur dan Pekerjaan, di Ruang Obgyn RSUD Lakipadada Kabupaten Tana Toraja , 2013. di lakukan pada bulan Januari - Agustus Tahun 2013. Populasi dalam penelitian ini adalah keseluruhan data tentang wanita yang mengalami seksio caesarea di ruang obgyn yang telah diregister di RSUD Lakipadada tahun 2013. Sampel dalam penelitian ini adalah hanya wanita yang menjalani seksio caesarea dalam kurun waktu januari - desember 2013 dengan jumlah 457 responden.

\section{Pengumpulan Data}

1. Data Primer

Untuk memproleh data dilakukan dengan cara menyebarkan kuesioner kepada responden dan melakukan observasi terhadap responden.

2. Data Sekunder

Data Sekunder didapatkan dari instansi terkait yaitu rekam medik di RSUD Lakipadada.

Pengolahan Data:

1. Editing adalah upaya untuk memeriksa kembali kebenaran data yang diproleh atau dikumpulkan.

2. Coding merupakan kegiatan pemberian kode numeric (angka) terhadap data yang terdiri atas beberapa kategori

3. Data Entry

Data Entry adalah kegiatan memasukkan data yang telah dikumpulkan kedalam master tabel atau database computer

\section{HASIL PENELITIAN}

1. Karakteristik Responden

Tabel 1. Distribusi karakteristik responden Di RSUD Lakipadada Kabupaten Tana Toraja. $(n=457)$

\begin{tabular}{|c|c|c|}
\hline Karakteristik & $\mathrm{n}$ & $\%$ \\
\hline Umur & & $30,85 \%$ \\
Resiko Tinggi \\
$(<20>35$ Tahun $)$ & $\begin{array}{c}311 \\
\text { Resiko Rendah }\end{array}$ & $\begin{array}{c}69,15 \% \\
100 \%\end{array}$ \\
\hline $\begin{array}{c}\text { Pekerjaan } \\
\text { IRT } \\
\text { Pegawai }\end{array}$ & $\begin{array}{c}410 \\
47\end{array}$ & $\begin{array}{c}89,71 \% \\
10,29 \%\end{array}$ \\
\hline Sectio Caesarea & 457 & $77,99 \%$ \\
\hline Non Sectio & 129 & $22,01 \%$ \\
Caesarea & & \\
\hline
\end{tabular}

Berdasarkan tabel 1. diatas menunjukkan bahwa dari 457 responden yang mengalami Sectio Caesarea ditemukan pada kelompok resiko tinggi $<20$ dan $>35$ tahun dengan jumlah 141 responden $(30,85 \%)$, kelompok resiko rendah 20-35 tahun sebanyak 316 responden $(69,15 \%)$. Dengan kata lain bahwa persentase Sectio Caesarea lebih tinggi pada kelompok umur resiko rendah 20-35 tahun. dimana ibu dengan pekerjaan IRT sebanyak 410 responden $(89,71 \%)$, Sedangkan ibu dengan pekerjaan pegawai 47 responden $(10,28$ $\%)$. Sectio Caesarea sebanyak 457 responden $(77,99 \%)$ dan non Sectio Caesarea sebanyak $129(22,01)$.

2. Analisis Univariat

Tabel 2. Distribusi Persalinan sectio caesarea Di RSUD Lakipadada Kabupaten Tana Toraja JanuariDesember 2013.

\begin{tabular}{|l|l|c|}
\hline Bulan & Frekuensi & Persentase \\
\hline Januari & $\begin{array}{l}42 \\
\text { responden }\end{array}$ & $9,20 \%$ \\
\hline Februari & $\begin{array}{l}35 \\
\text { responden }\end{array}$ & $7.65 \%$ \\
\hline Maret & $\begin{array}{l}32 \\
\text { responden }\end{array}$ & $7.00 \%$ \\
\hline April & $\begin{array}{l}38 \\
\text { responden }\end{array}$ & $8.31 \%$ \\
\hline Mei & $\begin{array}{l}36 \\
\text { responden }\end{array}$ & $7.88 \%$ \\
\hline Juni & $\begin{array}{l}44 \\
\text { responden }\end{array}$ & $9.62 \%$ \\
\hline Juli & $\begin{array}{l}39 \\
\text { responden }\end{array}$ & $8.53 \%$ \\
\hline Agustus & $\begin{array}{l}32 \\
\text { responden }\end{array}$ & $7.00 \%$ \\
\hline September & $\begin{array}{l}36 \\
\text { responden }\end{array}$ & $7.88 \%$ \\
\hline Oktober & $\begin{array}{l}47 \\
\text { responden }\end{array}$ & $10.28 \%$ \\
\hline November & $\begin{array}{l}33 \\
\text { responden }\end{array}$ & $7.22 \%$ \\
\hline Desember & $\begin{array}{l}43 \\
\text { responden }\end{array}$ & $10.29 \%$ \\
\hline Jumlah & $\begin{array}{l}457 \\
\text { responden }\end{array}$ & $100 \%$ \\
\hline
\end{tabular}

Berdasarkan tabel 2. Menunjukkan bahwa jumlah ibu bersalin secara Sectio Caesarea sebanyak 457 terhitung dari januari - desember 2013.

\section{PEMBAHASAN}

Sectio Caesarea adalah suatu pembedahan untuk melahirkan janin lewat insisi pada dinding abdomen dan uterus. 
Proses kelahiran, persalinan dan nifas tidak senantiasa berlangsung secara fisiologi namun dapat juga secara patolologi.dan dapat mendapatkan penanganan yang sebaikbaiknya.(William,R, 2012,hal 634). Dari hasil pengolahan data yang telah dilakukan ditemukan persalinan 586 responden post partum dan kasus sectio caesarea sebanyak 457 responden ( $77,99 \%)$ yang mendapat pelayanan di RSUD Lakipadada Kabupaten Tana Toraja Tahun 2013.Karakteristik tentang variabel penelitian ini terdapat pembahasan sesuai dengan faktor-faktor yang diteliti berkaitan dengan Sectio Caesarea.Umur. Dari hasil penelitian yang dilakukan yang dilihat dari kelompok umur yang paling banyak menjalani Sectio Caesarea yaitu umur 20-35 tahun sebanyak 316 responden ( 69,15\% ).Umur paling tinggi yaitu 55 tahun dan umur paling rendah yaitu 14 tahun.

Sectio caesarea banyak di dapatkan pada umur 20-35 tahun karena tidak ingin merasakan nyeri hebat, merasakan persalinan dengan proses yang relatif cepat, faktor estetika (tidak ingin elastisitas vagina berubah), bisa menentukan tanggal kelahiran bayi, dan adanya rekomendasi kerabat (Sari, 2009). Dari data diatas, menimbulkan pertanyaan tersendiri karena berdasarkan angka kejadian sectio caesarea kehamilan lebih disarankan pada usia $<20$ tahun atau >35 tahun dengan alasan jumlah kejadian operasi caesarea pada umur $<20$ tahun dan >35 tahun jumlah kejadiannya lebih sedikit dibandingkan dengan umur ibu antara20-35 tahun. Sedangkan berdasarkan teori, kehamilan pada usia $<20$ tahun bisa menimbulkan masalah. Beberapa risiko yang bisa terjadi pada kehamilan di usia $<20$ tahun adalah kecenderungan naiknya tekanan darah dan pertumbuhan janin terhambat.Sedangkan kehamilan di atas umur 35 tahun masuk dalam kondisi kehamilan berisiko tinggi.

Risiko terhadap janin biasanya terkait dengan terjadinya kelainan kongenital.Selain itu, risiko terhadap wanita berkaitan dengan timbulnya penyakit yang sebelumnya tidak dimiliki oleh wanita tersebut dan pada saat kehamilan penyakit tersebut muncul, misalnya penyakit yang berhubungan dengan jantung.Usia merupakan salah satu tolak ukur kesiapan seresponden ibu untuk melahirkan, dimana usia ideal untuk menjalani proses kehamilan dan persalinan adalah usia 20-35 tahun. Wanita berusia kurang dari 20 tahun biasanya memiliki kondisi psikis yang belum matang serta kemampuan finansial yang kurang mendukung, sementara wanita berusia lebih dari 35 tahun cenderung mengalami penurunan kemampuan reproduksi (Harnowo,
2013). Umur adalah lamanya seseresponden hidup. Umur ibu yang terlalu muda ( $<20$ tahun) atau (>35 tahun ) sangat memegang peran yang penting untuk proses kehamilan, persalinan, dan nifas.

Perkembangan alat reproduksi umur ibu yang terlalu muda belum matang sehingga banyak resiko yang dapat di timbulkan sedangkan umur ibu yang terlalu tua, alat-alat reproduksi mengalami proses degenerasi atau kemunduran sehingga dapat mempersulit proses kehamilan, persalinan, dan nifas.(Sugono D,2009, hal 248 ). Dengan melihat pendapat Sugono maka di simpulkan bahwa pada usia muda yaitu kurang dari 20 tahun organ reproduksi belum sempurna secara keseluruhan dan kejiwaan belum matang dan belum siap untuk menjadi ibu dan belum mampu menerima kehamilannya, yang akan mengakibatkan terjadinya peningkatan angka kematian ibu dan janin. Sedangkan kehamilan diatas 35 tahun memiliki resiko tiga kali terjadinya persalinan sectio caesarea di bandingkan umur di bawah 35 tahun. Pekerjaan dalam arti luas adalah pekerjaan utama yang ditekuni oleh manusia.Dalam arti sempit, istilah pekerjaan digunakan untuk suatu tugas atau kerja yang menghasilkan uang bagi seseresponden, dalam kehidupan sehari-hari istilah ini dianggap sama dengan profesi. Dari hasil penelitian di RSUD Lakipadada, Sectio Caesarea berdasarkan pekerjaan di temukan lebih banyak pada IRT dengan jumlah 410 responden (89,71 \%). Dibandingkan dengan Pegawai sebanyak 47 responden $(10,29 \%)$. Dari hasil penelitian lebih banyak di temukan pada ibu rumah tangga dengan Sectio Caesarea, yang seharusnya lebih banyak pada pegawai karena lebih banyak kesibukan, di lihat dari majunya ilmu pengetahuan dan teknologi akan memicu manusia untuk lebih banyak mengetahui segala sesuatu.Sehingga kepada siapa pun yang ingin melahirkan bisa mengambil keputusan apa pun.Apakah ingin melahirkan normal atau dengan Sectio Caesarea dengan hal yang tertentu.Dengan meningkatnya angka Sectio Caesarea yang di rawat di RSUD Lakipadada Tahun 2013 disebabkan karena beberapa hal misalnya untuk menghindari rasa nyeri, faktor pengetahuan, keluarga yang mapan, ketuban pecah dini, His yang lemah, gamely, dan kelainan letak

\section{KESIMPULAN}

Dari hasil penelitian dan pengolahan data tentang persalinan di RSUD Lakipadada Kabupaten Tana Toraja Tahun 2013, maka dapat disimpulkan sebagai berikut 
:Jumlahpersalinan dengan sectio caesarea di RSUD Lakipadada Tana Toraja Tahun 2013 sebanyak 457 responden $(77,99 \%)$. Gambaran umum Sectio Caesarea berdasarkan umur dimana persentase yang mengalami Sectio Caesarea lebih banyak yaitu pada umur resiko rendah (20-35) dengan jumlah 316 responden $(69,15 \%)$. Gambaran umum Sectio Caesarea berdasarkan pekerjaan yaitu dimana persentase yang mengalami Sectio Caesarea lebih banyak yaitu pada ibu IRT 410 responden $(89,7 \%)$

\section{SARAN}

1. Diharapkan kepada responden responden tua, dan keluarga ( responden - responden terdekat) selalu memberikan support dalam bentuk motivasi dan juga dalam bentuk finansial kepada ibu hamil pada face trimester I-III agar pada saat persalinan dapat melahirkan dengan normal.

2. Diharapkan kepada peneliti selanjutnya agar melakukan penelitian factor penyebab persalinan SC.

\section{DAFTAR PUSTAKA}

Agreni L, 2012, Konsep Section Caesarea di akses tanggal 15 juli 2014, http//digilip.unimus.ac.id/files/disk1//123jtptunimus-gdl

Dewi dan Indrawati, 2010.Sejarah Perkembangan Sectio caesarea Eko Budiarto, 2005,Rumus Analisa Data diakses tanggal 17 juli 2014

Jitowiyono Sugeng, Kristiyanasari. 2012. Asuhan Keprawatan Post Operasi.Yogyakarta

Kasdu, 2003, Perkembangan Sectio Caesarea

Manjoer Arief, 2010, Pengertian Eklamsia

Monica, Ester. 2006. Asuhan Kebidanan. Jakarta :EGC

Notoadmojo, 2010.Kerangka Konsep

Prawirohardjo. 2007. Ilmu bedah kebidanan. Jakarta :KDT

Profil Rumah Sakit Umum Daerah Lakipadada, 2014.Tana Toraja.Makale

Rekam medic RSUD Lakipadada. 2013. Angka kejadian section caesarea . Kabupaten Tana Toraja Makale

Reeder,dkk, 2003, ilmu bedah kebidanan. Jakarta :EGC

Rustam, Mocthar. 2000. Sinopsis Obstetri .Jakarta :EGC

Sarwono, 2010, Sinopsis Obstetri.Jakarta : EGC

Satriana, 2012, pengertian Pekerjaan Diakses pada tanggal 15 juli 2014 http://Satrianadotorg.wordspress.com

Sekender RSB Pertiwi, 2008,data wilayah Makassar Diakses pada tanggal 15 juli 2014 www.blogspot.com/2012/12

Sharjon J.Reeder,dkk. 2003.Keperawatan matenitas . Jakarta :EGC. 